\title{
Integration of soil structure variations with time and space into models for crop management. A review
}

\author{
J. Roger-EstradE ${ }^{1 *}$, G. RICHARD ${ }^{2}$, A.R. DEXTER ${ }^{2,3}$, H. BOIZARD $^{4}$, S. DE TOURDONNET $^{1}$, M. BERTRAND $^{5}$, \\ J. CANEILL ${ }^{6}$ \\ ${ }^{1}$ AgroParisTech, Département SIAFEE, Centre de Grignon, BP 01, 78850 Thiverval-Grignon, France \\ 2 INRA UR0272 Science du Sol, Centre de Recherche d'Orléans, 2163 Av. de la Pomme de Pin, CS 40001, Ardon, 45075 Orléans Cedex 2, France \\ ${ }^{3}$ Associate Scientist, Le Studium ${ }^{\circledR}, 45000$ Orléans, France \\ ${ }^{4}$ INRA, US 1158, Agrosystèmes \& impacts environnementaux carbone-azote, Estrées-Mons, BP 50136, 80203 Péronne, France \\ ${ }^{5}$ INRA UMR 211 INRA AgroParisTech, BP 01, 78850 Thiverval-Grignon, France \\ ${ }^{6}$ INRA, UMR Biologie et Gestion des Adventices, 17 rue Sully, BP 86510, 21065 Dijon Cedex, France
}

(Accepted 8 September 2008)

\begin{abstract}
Soil structure plays a major role in the design of new crop management systems. For instance, the transition from conventional to no-tillage changes soil structure, which, in turn, has implications on crop yield greenhouse gas emissions, and pesticide and nitrate leaching. Modelling soil structure at field scale faces two main issues: (1) the spatial variability and (2) the temporal variability. Here, we review how spatial variability of soil structure is taken into account in water transfer models at field scale. We discuss the effects of soil structure on hydraulic properties. We present options to model soil structure effects using pedotransfer functions or calculations based on pore network geometry. Then we review studies on water transfer. Here, we show the utility of one-dimensional (1-D) and 2-D models, and the range of soil profile partitions. In the second part, we study a mean to model the temporal variation of soil structure. We propose an indicator of soil structure dynamics based on the proportion of compacted clods in the tilled layer. This indicator was measured from the observation face of soil pits. We studied this indicator in a long-term field experiment involving various risks of compaction. The results showed that this indicator gave a more precise description of the time course changes in soil structure than the mean soil bulk density measured on the same experimental plots. Lastly, we discuss the principles of a model that predicts the evolution of this indicator under different soil tillage and climatic conditions. This model can be used to evaluate the effects of different crop management systems on soil structure and soil water transfer.
\end{abstract}

soil structure / crop management / tillage / water transfer / model

\section{INTRODUCTION}

For many years, conventional tillage involving mouldboard ploughing was used in agriculture to control the development of weeds, to incorporate crop residues into soil, to recycle leached nutrients in surface soil and to prepare a favourable tilth before seeding (Dexter et al., 1983). However, for multiple reasons such as cost reduction, increase in work productivity, prevention of soil erosion and protection of soil fauna, ploughless or reduced soil tillage systems have been introduced, and co-exist with conventional systems in many parts of the world. In some regions such as Brazil and Argentina the non-ploughed areas are increasing exponentially, together with

*Corresponding author: Jean.Roger_Estrade@agroparistech.fr the use of herbicides and genetically-modified (GM) crops. These changes happen very quickly and they profoundly modify the environmental conditions of crop production. In many cases, particularly in Western Europe, their sustainability has still to be ascertained (Carter, 1994). This diversification of tillage management systems induces variation in soil structure within a given territory, where, more often, different tillage systems co-exist. It is therefore necessary to coordinate the design of new crop management systems at the catchment level when addressing problems such as erosion control, or on the regional scale if the mitigation of greenhouse gas emissions is concerned (Ball et al., 1999). This territorial aspect of the design of crop management systems will not be discussed in this paper, where we will consider soil structure only on the field scale. 
Soil structure varies considerably within a field (Roger-Estrade et al., 2000). Indeed, cultivated soils are subjected to mechanical stresses which are not applied homogeneously to the soil. For instance, compaction during traffic affects only the soil volume beneath the wheel tracks and soil fragmentation depends on tillage depth. Moreover, soil strength depends greatly on soil water pressure which also varies, especially with depth. Consequently, the spatial variation in soil structure is very important, both in the direction perpendicular to the traffic direction and in depth. This variability has consequences on the soil functioning, e.g. water transfers (Stenitzer and Murer, 2003), nitrous oxide emission (Röver et al., 1999), mineralisation (Guérif et al., 2001), seedling emergence or root establishment. It therefore has an impact on the performance, productive as well as environmental, of the crop management systems, and must be addressed in models used for their design.

The temporal dimension of soil structure variation is also a key point to consider. Indeed, new conditions for soil structure dynamics are created by the diversification of tillage management and the widening range of soil moisture at cultivation due to the increase in the area cultivated per capita. Consequently, changes with time in several biological, chemical and physical soil properties are also modified. For instance, changes with time in the internal structure of fragments of tilled soils were quantified on sections cut on 400-mm blocks of resinimpregnated soil by Dexter (1976), Ojeniyi and Dexter (1983), and Dexter et al. (1983). It was observed that there is a change in the topology of the soil structure with time. Immediately after tillage, the sections show "islands" of aggregates in a "sea" of pore space. With time, the aggregates become joined together so that the observed structures change to be "islands" of pore space surrounded by a sea of soil matrix, formed from modified aggregates. Aspects of these changes in soil internal structure have been modelled by Or et al. (2000) and by Liej et al. (2002). Other studies have shown that the remaining inter-aggregate pore spaces become cut off from each other when the macroporosity is reduced to about 10 percent (Davis et al., 1973). Such cutting off and isolation of macropores can cause sudden and dramatic reductions in saturated hydraulic conductivity and air permeability.

In conventional agriculture, deep tillage was an efficient way to recover damaged soil structure, even if this operation could also damage the soil, when it is performed while soil water content is excessive, for instance. With no or only shallow tillage, soil structure recovery generally takes far more time (Horn, 1995) than with deep tillage, depending of course on soil type, intensity of weathering or biological activity. Therefore, periods in the crop cycle during which soil structure is suboptimal become more and more frequent, and this must be taken into account when designing new crop management systems.

Generally, crop models do not consider changes with time in the soil structure and the associated soil properties. Moreover, crop models are mainly one-dimensional, using a constant bulk density as a descriptor of soil structure, e.g. APSIM (McCown et al., 1996), CERES (Ritchie et al., 1998) and STICS (Brisson et al., 1998). Therefore, an improvement of these models would be the incorporation of a sub-model that describes the time variation in soil structure. This would enable simulation of the effects of agricultural practices during a whole crop rotation.

This article comprises two main sections: a review of how spatial variation in soil structure is taken into account. To illustrate the consequences of this, we chose the specific subject of water transfer modelling. This particular aspect of the consequence of soil structure was chosen because of the importance of water transfer in the environmental impact of cropping systems. The second section deals with the changes with time in soil structure, as a function of crop system management.

\section{INTEGRATING SPATIAL VARIATION IN SOIL STRUCTURE INTO WATER TRANSFER MODELS}

Knowledge of the hydraulic properties of cultivated soils on the field scale is essential for the understanding and prediction of the main processes in the water cycle: infiltration, runoff, evaporation and redistribution, which in turn affect crop performance, e.g. germination and water uptake by roots, and aspects of environmental quality, e.g. erosion, nitrate and pesticide leaching, and $\mathrm{N}_{2} \mathrm{O}$ emissions. Hydraulic properties depend on the geometry of the pore network which is determined by soil texture as well as its structure, i.e. the size of the soil particles and the way they are packed together (Green et al., 2003). In naturally-formed aggregates, hydraulic intra-aggregate properties are affected by the initial formation of a dense particle arrangement with fine pores through repeated wetting and drying. Such aggregates have a continuous pore system which results in a high water availability. On the macroscale, elementary soil volumes retain more water near saturation when they are more porous or when soil fragments are large (with large macropores between them). Therefore, the saturated hydraulic conductivity (Ks) increases when the soil bulk density decreases, or when the soil fragments are large. When water is not located in the pore space between soil fragments an increase in bulk density leads directly to an increase in volumetric water content, by definition (Reicosky et al., 1981). When the soil water content is characterised by the gravimetric water content or the soil water ratio rather than the volumetric soil water content, it appears that an increase in bulk density, i.e. soil compaction, sometimes leads to an increase in water content (Richard et al., 2001) and sometimes not (Reicosky et al., 1981; Sillon et al., 2003). Which effect predominates depends on whether the compaction affects only the macroporosity or both macro- and microporosity. Hydraulic conductivity depends on the continuity of the small pores between soil fragments under these moisture conditions. Hydraulic conductivity at low water potentials, i.e. at large negative water potentials, is greater for a dense tilled layer than for a loose tilled layer (Sillon et al., 2003), or for an aggregated tilled layer composed of small aggregates than one made up of large ones (Hadas, 1997). In both cases, it can be presumed that the area of contact between soil fragments, i.e. the water-filled pore continuity, is greater in a compacted 
tilled layer than in a soil layer composed of small aggregates. However, hydraulic conductivity generally varies by a factor less than 10 between the two situations.

To predict the effect of soil structure on soil hydraulic properties, retention and hydraulic conductivity curves are used (Millán and González-Posada, 2005; Sain et al., 2006). They can be described with several functions: van Genuchten, Brooks and Corey, Mualem, or Burdine. Changes with soil structure in the values of the coefficients can be assessed by indirect or direct methods. Indirect methods consist of mathematical relationships, e.g. pedotransfer functions, between these coefficients and several characteristics of soil structure, most often soil bulk density and soil texture: percentages of clay, silt, sand and organic carbon. With direct methods the soil hydraulic properties are calculated directly from the geometry of the pore network. The pore size distribution of the dried soil can be obtained from mercury intrusion measurements or of the moist soil by tomography. It can also be calculated from the particle and aggregate size distribution (Arya and Paris, 1981).

Models of water flux in soils are based on Richards' equation. This equation describes water transfer from the generalised law of Darcy on a macroscopic scale for which the soil, which is a polyphasic porous media, can be considered as homogeneous and without any discontinuity. When there are macropores in the soil, i.e. voids from tillage, cracks from climate, earthworm channels and root channels, water flux is not uniform because water is transferred much more quickly in the macropores than in the soil matrix, and consequently, preferential flows can occur. Darcy's law, when applied to a soil volume with macropores, cannot fully describe water flux. In that case, the soil pore volume may be divided into at least two subvolumes: the microporosity, or intra-aggregate porosity, and the macroposity, or inter-aggregate porosity. Water flux is then described for each type of porosity with different soil properties and/or physical laws, and between the two types of porosity. Within the microporosity, water flow is still described by Darcy's law. Within the macroporosity, water flux can be calculated with several laws: Darcy, Poiseuille, Green and Ampt, or kinematic waves (Simunek et al., 2003).

Numerous models of soil water flow have been described in the literature. They can be one-dimensional, i.e. as a function of soil depth, two-dimensional, i.e. within a soil profile, or three-dimensional models. They can integrate (i) only Darcy's law, (ii) Darcy's law and a specific law for preferential flows, or (iii) only a specific law for preferential flows. Threedimensional models have mainly been applied to laboratory soil columns where water is transferred only in the macroporosity using Poiseuille's law (Delerue and Perrier, 1999).

The various approaches to integrating the soil structure on the field scale concern 1-D and 2-D models based on Darcy's laws. The first approach consists of applying a 1-D model to soil layers which differ in soil structure due to tillage or compaction. Linden (1982) was one of the first authors to analyse the effect of a change in bulk density of the tilled layer on evaporation with model simulations. He analysed the theoretical effect of a change in bulk density on hydraulic properties and showed that tillage reduced evaporation (from 18 to $12 \mathrm{~mm}$ after 10 days). Richard et al. (2001) and Sillon et al. (2003) have used such models to estimate the change in hydraulic conductivity for soil layers with contrasted bulk density using an inverse method. Hydraulic conductivity was calculated for the whole range of soil water content (even for the dry state) from field measurements of change in soil water content under natural climate. They showed that soil layers with a high bulk density remained wetter near the soil surface than soil layers with a low bulk density during a dry period.

It should be noted that values of hydraulic conductivity estimated by inverse methods are, in reality, effective hydraulic conductivities. They do not distinguish between water flow through the soil matrix to the soil surface and transport of water in the vapour phase through the macropore space caused by convective air movements resulting from fluctuations of atmospheric pressure or temperature (Farrell et al., 1966; Kimball and Lemon, 1971). These air movements can become significant when inter-aggregate macropores are larger than about $4 \mathrm{~mm}$ diameter (Ojeniyi and Dexter, 1984).

De Tourdonnet (1998) has proposed distributing 1-D numerical models to take into account the spatial variation in soil structure. Studying water transfer in a greenhouse (plastic tunnel), he combined the heterogeneity of soil structure (two levels of compaction, i.e. under or outside wheel tracks) with that of irrigation (between 54\% and 107\% of the mean water supply). He defined seven zones from the centre to the border of the tunnel and studied, in particular, the effect of this heterogeneity of greenhouse conditions on nitrate leaching.

The possible influence of lateral water transfer has led several authors to propose 2-D models of water transfer. Benjamin et al. (1990) have proposed a 2-D water and heat simulation model to compare water and heat flow from a flat or a ridge soil surface (with tall or short ridges). They took into account heterogeneity of the physical properties within a soil profile distinguishing three zones: the plant row, the untracked interrow and the wheel-tracked interrow. Benjamin et al. (1990) showed that water potential at the top of the wheel-tracked interrow remained less negative than at the top of the untracked one during a dry period. However, as for Sillon et al. (2003), only dry periods were simulated. Lamandé (2003) and Ndiaye et al. (2007) have proposed a soil profile partition similar to that of Benjamin et al. (1990) to simulate (using HYDRUS-2D) the effect of the heterogeneity of the soil structure under a maize crop on water infiltration after a rainfall event. For instance, Lamandé (2003) distinguished four zones under a maize crop: non-compacted, interrow (untracked), compacted interrow (wheel-tracks) and plough pan. He showed that the water flux at the bottom of the plough pan was determined mainly by the hydraulic properties of the non-compacted interrow, where water could infiltrate, rather than that of the compacted interrow, where water could not infiltrate.

The studies of Benjamin et al. (1990), Lamandé (2003) and Ndiaye et al. (2007) showed that 2-D models can be used to evaluate the effect of heterogeneity of soil structure both on evaporation during dry periods and on infiltration during rainy periods. However, the geometry of the zones of the soil profile defined by these authors was quite simple. All the limits were either vertical or horizontal, while more complicated geometry 
can be created by tillage. Coutadeur et al. (2002) used the same partitioning as Lamandé (2003) and identified, within the untracked soil compartment, two soil zones: compacted and porous zones. Compacted zones in the untracked compartment resulted from the action of the mouldboard plough, i.e. the fragmentation and displacement of previously-compacted soil areas. The contour of the compacted zones was accounted for using the adaptative mesh system of HYDRUS-2D (more than 10000 triangles and 6000 nodes were needed). Coutadeur et al. (2002) could then evaluate the effect of the position and shape of the compacted zones on water infiltration.

However, none of the water flow models presently in use considers changes with time in the soil structure and the associated hydraulic properties, and this is also true for the crop models. Therefore, these models could be improved by linking the water flow models with the models that describe the change in soil structure with time (e.g. Roger-Estrade et al., 2000). This should enable simulation of the effect of agricultural practices on hydraulic properties during a whole crop cycle or during a crop sequence.

\section{TAKING INTO ACCOUNT THE TEMPORAL VARIATION IN SOIL STRUCTURE}

\subsection{An indicator of soil structure dynamics}

Until now, most studies on soil structure dynamics have focused on only one of the processes involved; displacement, compaction or fragmentation (Dexter and Birkás, 2004; Keller et al., 2007). Moreover, they generally involve only a small volume of soil, such as that immediately under a tyre or in front of a tine. Their results could perhaps be extended to a heterogeneous field whose tilled layer is composed of many such volumes, each having a specific density and $\mathrm{S}$ value (Dexter, 2004). It should be noted that pedo-transfer functions are available for prediction of values of S. However, the use of these results to forecast structure dynamics remains difficult because temporal changes are due to a complex succession of different processes. Aspects of this subject need to be further developed to take structure dynamics into account. Until that has been done, crop management design requires the use of a global model such as the one we present in this paper, even if the processes involved in structure dynamics are represented in a rather simplified way.

We have developed a field method based on a morphological description of soil structure, which is described in detail in Roger-Estrade et al. (2004). One of our major concerns was to describe and analyse not only the spatial variation in soil structure but also its dynamics. This led us to propose an indicator of the effect of the crop management system on soil structure. This indicator (Roger-Estrade et al., 2000) is based on the evaluation of the proportion of severely-compacted clods and zones in the tilled layer (or the equivalent soil volume, i.e. roughly the first thirty centimetres of soil in non-tilled situations, the exact value depending on the depth of the last ploughing). This evaluation is made on the vertical observation face of a pit, dug far from the edges of the field and chosen to be large enough to take into account the pattern of wheel
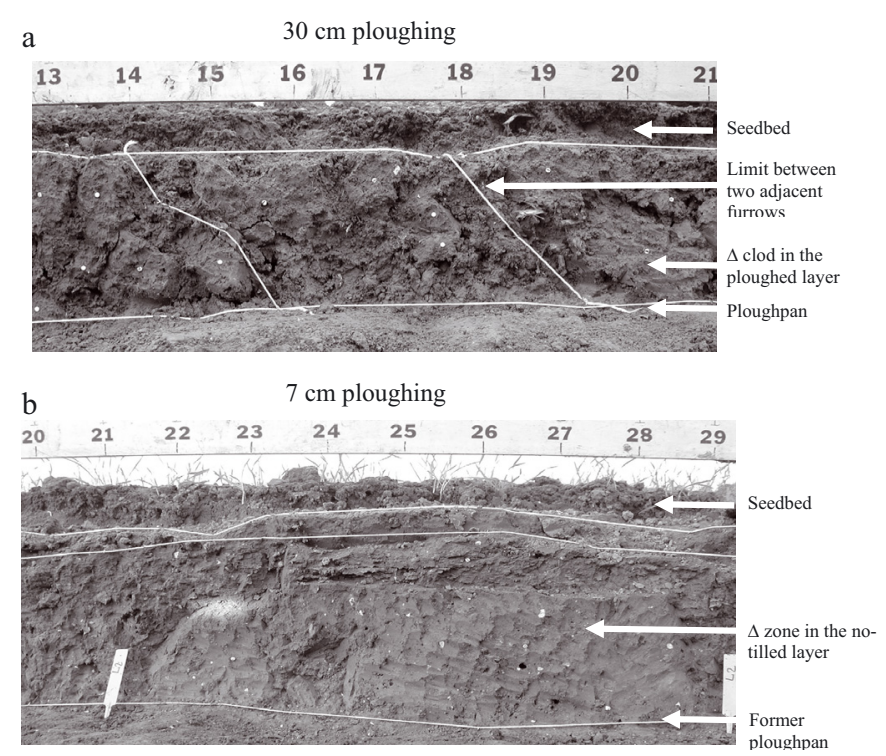

Figure 1. Photographs of the observation faces of two soil profiles (a) in the LCR-P plot, (b) in the HCR-NP plot of the long-term field experiment in Mons. LCR-P: deep ploughing (0.3 $\mathrm{m}$ depth). LCR-NP reduced tillage ( $0.07 \mathrm{~m}$ depth). The distance between two successive numbers is $10 \mathrm{~cm}$.

tracks created by the successive field operations. The location and width of the pit is decided depending on the geometry (tyre size, working width) and the location of the passes of the tillage tools, tractor and harvesting wheel tracks. It is also slightly deeper than the greatest working depth of the tillage tools. Once the pit is dug, the observation face is prepared so that one can distinguish the zones and clods in the soil resulting from severe compaction, i.e. without any visible structural porosity. These zones, located under the recent wheel tracks, and clods, resulting from the fragmentation by the plough of existing compacted zones, are called $\Delta$ clods and zones (see Roger-Estrade et al. (2004) for the precise definition and properties of $\Delta$ structure). Digital photographs of the observation face were taken in the field, and transferred onto a computer where the limits of the $\Delta$ zones and clods were drawn and digitised for image analysis. The areas and the locations of the $\Delta$ zones were determined, as well as the thickness of the tilled layer. The percentage of $\Delta$ areas was given by the ratio of the cumulated $\Delta$ surface area to the total surface area of the tilled layer. This percentage was measured just after crop establishment. Examples of two observation faces are shown in Figure 1.

\subsection{Time course changes in soil structure}

Bulk density and the above-mentioned indicator were simultaneously measured to evaluate soil structure dynamics in a field experiment where two crop management systems were compared. In the first crop management system, the crop sequence was pea (Pisum sativum L.)-winter wheat (Triticum aestivum)- flax (Linum usitatissimum $\mathrm{L}$.)-winter wheat. The 
wheat was sown in early autumn. The pea and flax were sown in early spring. This crop management system, in which compaction risk is low, was labelled LCR for Low Compaction Risk. In LCR plots, two types of tillage were performed from 1999: (1) deep (0.3 m) ploughing with a mouldboard plough (LCR-P treatment) and (2) reduced tillage, in which only a superficial $(0.07 \mathrm{~m}$ depth) chiselling was performed to prepare the soil before sowing (LCR-NP treatment). In the second crop management system, the crop sequence was maize (Zea mays L.)-winter wheat-sugar beet (Beta vulgaris $\mathrm{L}$.)-winter wheat. In this system, sugar beet and maize were sown as soon as the seed bed was warm enough for germination, whatever the soil moisture conditions, and were harvested as late as possible, generally at the end of autumn, whatever the soil moisture conditions. This crop management system was labelled HCR (for High Compaction Risk). As for the other system, the same two tillage systems were compared from 1999, giving the two following treatments: HCR-P and HCR-NP.

In all the experimental trials, the plots were large enough to allow use of the farmers' equipment and crop management was performed classically for this French area for industrial crop production (details of the cultivation operations are given in Boizard et al., 2002). In four plots of this experiment, we made measurements of the mean bulk density and the percentage of $\Delta$ clods and zones in the $5-30 \mathrm{~cm}$ soil layer at seven dates between 1999 (just after ploughing was interrupted on half of the plots) and 2006. The measurements of the $\Delta$ zones were made just after sowing of the crops, in the layer between the bottom of the seedbed and the present or most recent plough pan. The mean dry bulk density was measured after each sowing on unwheeled zones with a transmission ray probe (10 replicates) up to a depth of $0.35 \mathrm{~m}$ at every $3.5 \mathrm{~cm}$ depth. The results are plotted in Figure 2.

After two years, the ploughed and non-ploughed parts of the experiment exhibited significant and constant differences in mean bulk density (Fig. 1a), whatever the crop sequence. This result is classically explained considering that undisturbed soil is denser than regularly-ploughed soil (Guérif, 1994; Hamza and Anderson, 2005). Conversely, change in bulk density over time was more similar between the HCR and the LCR plots than between the P and NP treatments. There was no significant difference between HCR and LCR for the ploughed treatments. In reduced tillage, bulk density depended on the cropping system and year. In LCR, values of bulk density fluctuated greatly around a mean value (ca. $1.45 \mathrm{~g} . \mathrm{cm}^{-3}$ ). These variations were probably due to the changes from one year to another in the moisture conditions at sowing and harvesting. In HCR, the bulk density sharply increased in 2002. The sugar beet harvesting in 2001 caused particularly high compaction in these plots, because of the high soil water content in late autumn and the high proportion of the soil surface affected by traffic. The bulk density remained very high, between 1.52 and $1.58 \mathrm{~g} . \mathrm{cm}^{-3}$, during the following years, though there was no further severe compaction during field operations during the three years.

Figure $2 b$ shows that the ranking of the plots is different when the percentage of $\Delta$ clods is considered. At the beginning of the period, if bulk density was equivalent between the plots,

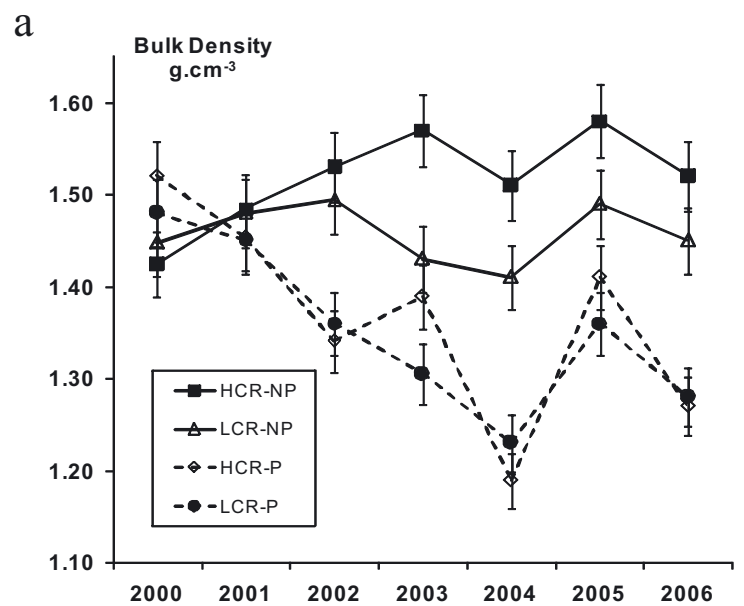

b

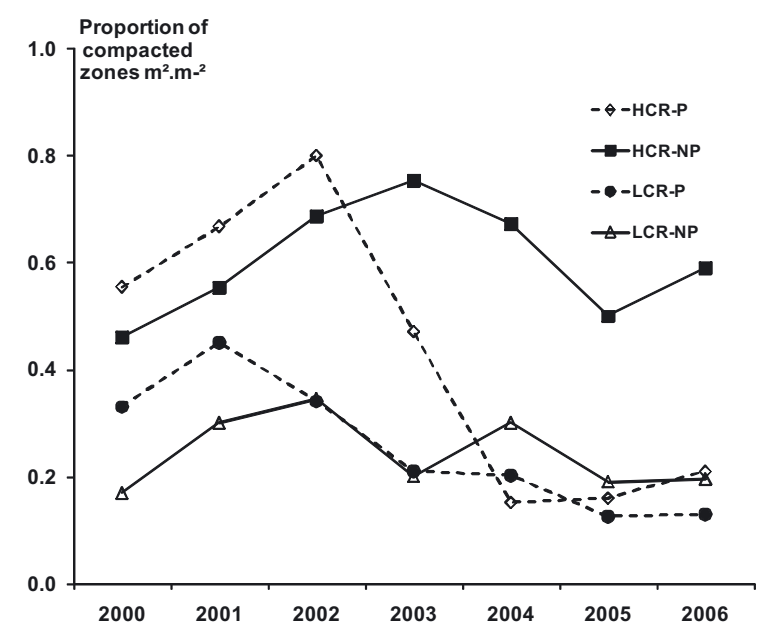

Figure 2. Change with time in (a) bulk density $\left(\mathrm{g} \cdot \mathrm{cm}^{-3}\right)$ and (b) the proportion of compacted zones ( $\Delta$ areas, $\mathrm{m}_{\mathrm{m}} \mathrm{m}^{-2}$ ) in four experimental plots of the long-term field experiment in Mons (vertical bars: confidence interval, $P=0.05$ ). HCR = cropping system with high compaction risk; $\mathrm{LCR}=$ cropping system with low compaction risk; $\mathrm{NP}=$ unploughed treatments; $\mathrm{P}=$ ploughed treatments.

the percentage of $\Delta$ clods was different. During the period, the percentage of $\Delta$ zones was higher in HCR plots, whatever the tillage mode, except in 2004, when the $\Delta$ percentage decreased sharply in the HCR ploughed plot and became similar to that of the LCR plots.

This dynamics can be explained by the fragmentation action of the plough. This tool creates mixed structures, with highly-fragmented zones separated by highly-compacted blocks (fragmented ancient $\Delta$ zones). This spatial variation on the layer scale is averaged out by the gamma ray probe, which gave higher bulk density values in the homogeneous NP treatments. The decrease in 2003 and 2004 can also be explained by the inverting action of the plough, which brought up compacted soil volumes towards the soil surface, causing their destruction by the intense fragmentation action of the secondary tillage tools. This effect was, in 2000, 2001 and 2002 annihilated by compaction during sowing, subsequent to 
the ploughing and/or harvesting. In the NP plots, compacted zones disappeared much more slowly in this loamy soil, where the climate action on soil structure is not very intense. These results are coherent with those of Watts and Dexter (1994), showing that the cloddiness of soil after tillage depends more on the soil water content at the time of the previous harvest than on the water content at the time of tillage, because of its effect on the compaction produced by the heavy equipment during harvest. This example shows that the soil structure dynamics results from a complex balance between fragmentation actions (reducing $\Delta$ volumes) and compaction ones (creating $\Delta$ zones). The information given by bulk density and the morphological approach are complementary. Moreover, the level of compaction risk associated with the crop management system is not sufficient to predict completely the structure dynamics.

\subsection{Modelling temporal changes in soil structure}

These considerations led us to propose a model, called SISOL, of soil structure dynamics, on the field scale, predicting the changes with time in the percentage of $\Delta$ zones within the tilled layer of cultivated fields.

\subsubsection{Principles of the model}

It is based on the following assumptions about the changes with time in the percentage of $\Delta$ zones (Roger-Estrade et al., 2000). The $\Delta$ zones are created only under the wheels, as a function of soil water content and equipment characteristics (Richard et al., 1999). Soil surface crusting is not considered significant because it affects only a small volume of soil.

The $\Delta$ zones are destroyed within the layer affected by superficial tillage (seed bed preparation and stubble disking). Here, weather reinforces the fragmentation produced by tillage: drying and wetting and/or freezing and thawing increase the sensitivity of $\Delta$ zones to fragmentation by subsequent tillage, or directly transform them into fine aggregates and individual particles. Consequently, all the $\Delta$ zones within the layer disturbed by superficial tillage are eliminated, whatever the moisture conditions. The action of weather is considered insufficient to fragment the $\Delta$ zones in the horizon located below the superficial layer. We also consider fragmentation caused by the plough to be insufficient to eliminate $\Delta$ zones (Coulomb et al., 1993). The destruction of $\Delta$ zones by soil macrofauna is also considered negligible. This is consistent with observations in fields that are tilled several times a year. The $\Delta$ zones are broken into smaller units (but not totally disintegrated into fragments $<2 \mathrm{~cm}$ ) during ploughing by the combined action of the share and the coulter of the plough. All causes of soil displacement other than ploughing (such as the formation of ruts) are neglected.

The modelled system corresponds to a two-dimensional soil layer, the depth of which is that of the thickness of the tilled layer. The profile width is chosen so that the pattern of wheel tracks created by the successive field operations is taken into
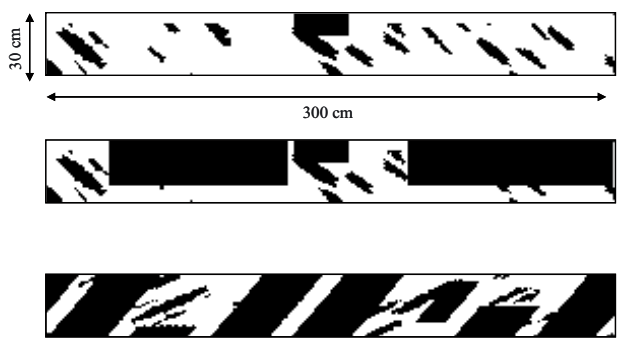

Figure 3. Examples of structural maps drawn by the simulation program after 3 cultivation operations. Each map corresponds to 9000 pixels. $\Delta$ pixels appear in black. (a) after sugar beet sowing; (b) after sugar beet harvesting; (c) after ploughing.

account. The tilled layer is represented in the model as a set of $1 \mathrm{~cm} \times 1 \mathrm{~cm}$ pixels, located regularly on a square grid. Each pixel is defined by its co-ordinates and a specific structure, $\Delta$ or non- $\Delta$. The pixel co-ordinates are modified during ploughing, for which the model calculates the lateral and vertical displacement of the soil. The structure of any individual pixel is changed depending on the soil condition and the kind of operation. The number of $\Delta$ gixels is computed by the program after each operation. The percentage of $\Delta$ areas is calculated as the ratio of the $\Delta$ pixels to the total number of pixels representing the tilled layer.

The initial locations of the $\Delta$ zones in the tilled layer are read by the program as an array of pixels. Each step of the program corresponds to a single cultivation operation. At each step, the equipment characteristics (axle load, tyre width, working depth) and the operation conditions (location of the wheel tracks, soil water content) are read from parameter files. The compaction procedure calculates the area of the $\Delta$ zones created under the wheels for each operation. The new coordinates of the pixels are recalculated as explained above when the operation is mouldboard ploughing. The pixels of the upper part of the soil profile are assigned a non- $\Delta$ structure for secondary tillage to a depth corresponding to the working depth of the tool. The program then calculates the ratio of the pixels with a $\Delta$ structure to the total number of pixels and draws a structural map of the tilled layer. This gives the percentages of $\Delta$ zones at each step. Simultaneously, the program draws structural maps, showing the location of the $\Delta$ pixels after each cultivation operation (Fig. 3).

\subsubsection{Evaluation and use of the model for designing crop management systems}

The SISOL model was evaluated on some ploughed plots belonging to the above-described field trial (Roger-Estrade et al., 2000). We verified that the general trend of the change over time in the percentage of $\Delta$ zones was correctly simulated by the model, which also predicted accurately the order of magnitude of the measured percentages of $\Delta$ areas. However, the program underestimated the decrease in the percentage of $\Delta$ zones. Indeed, the decrease could also be due to fragmentation occurring beneath the seed bed as a result of weather 


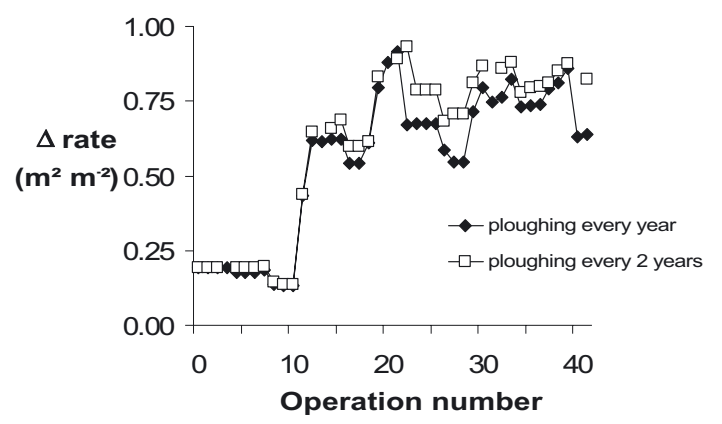

Figure 4. Simulation of the change in soil structure with two ploughing frequencies, i.e. ploughing every year or ploughing every two years, using the SISOL model.

or fauna, which are not taken into account at that depth in the model.

Despite this limitation, SISOL can be used to forecast the global effects of a cropping system on the changes over space and time in soil structure, on the field scale. An example of the use of SISOL is given in Figure 4. SISOL was used to predict the changes with time in soil structure in conditions similar to those of the above-presented field trial (HCR plots). The first scenario supposed that the plot was ploughed every year; in a second scenario, the plot was ploughed only every two years, before the sowing of wheat. The results showed that when the frequency of ploughing is decreased, the $\Delta$ percentage tends to increase, but in a rather small proportion. In these conditions, reduction in the frequency of ploughing to once every two years, saving fossil fuel, seems rather beneficial to the farmer.

\section{CONCLUSION}

This review outlines the three main following points. 1. Various models of water transfer are now available but the use of these models on real soil structure is still difficult for two main reasons: (i) the lack of measurements of the changes in hydraulic conductivity with soil structure, both near saturation and in dry conditions, and (ii) the limit of the Mualem-van Genuchten equations to formulate mathematically (with a single equation) the change in retention and hydraulic conductivity curves with water potential. 2 . The morphological description of soil structure described in this paper allows not only a precise analysis of the spatial variability in soil structure within the tilled horizons, but also 2-D modelling of the dynamics of soil structure in the field. 3. Preliminary investigations (Coutadeur et al., 2002; Ndiaye et al., 2007) suggest that the coupling of a 2-D model of soil structure and 2-D models of water transfer in soil could be a fruitful approach to modelling cropping system effects on water transfers in soil.

Acknowledgements: This work was carried out under the project "Soil degradation due to compaction" with the financial support of (1) the " ANR-Agence Nationale de la Recherche - The French National Research Agency" under the "Programme Agriculture et Développement Durable", project "ANR-05-PADD-013", (2) the Ministry in charge of the Environment under the programme GESSOL2 "Impact des pratiques agricoles sur le sol et les eaux".

\section{REFERENCES}

Arya L.M., Paris J.F. (1981) A physicoempirical model to predict the soil moisture characteristics from particle size distribution and bulk density data, Soil Sci. Soc. Am. J. 45, 1023-1030.

Ball B.C., Scott A., Parker J. P. (1999) Field $\mathrm{N}_{2} \mathrm{O}, \mathrm{CO}_{2}$ and $\mathrm{CH}_{4}$ fluxes in relation to tillage, compaction and soil quality in Scotland, Soil Till. Res. 53, 29-39.

Benjamin J.G., Blaybock A.D., Brown H.J., Cruse R.M. (1990) Ridge tillage effects on simulated water and heat transport, Soil Till. Res. $18,167-180$.

Boizard H., Richard G., Roger-Estrade J., Dürr C., Boiffin J. (2002) Cumulative effects of cropping systems on the structure of the tilled layer in northern France, Soil Till. Res. 64, 149-164.

Brisson N., Mary B., Ripoche D., Jeuffroy M.H., Ruget F., Nicoullaud B., Devienne-Baret F., Antonioletti R., Dürr C., Richard G., Beaudoin N., Recous S., Tayot X., Plenet D., Cellier P., Machet J.M., Meynard J.M., Delécolle R. (1998) STICS: a generic model for the simulation of crops and their water and nitrogen balances. I. Theory and parametrization applied to wheat and corn, Agronomie $18,311-346$.

Carter M.R. (1994) Strategies to overcome impediments to adoption of conservation tillage, in: Conservation Tillage in Temperate Agroecosystems, Carter M.R. (Ed.), CRC Press Inc., Boca Raton, USA, pp. 3-19.

Coulomb I., Caneill J., Manichon H. (1993) Comportement du sol au labour: méthode d'analyse et évaluation des conséquences de l'état structural initial du sol sur l'état transformé par le labour, Agronomie 13, 45-56.

Coutadeur C., Coquet Y., Roger-Estrade J. (2002) Variation of hydraulic conductivity in a tilled soil, Eur. J. Soil Sci. 53, 1-10.

Davis P.F., Dexter A.R., Tanner D.W. (1973) Isotropic compression of hypothetical and synthetic tilths, J. Terramech. 10, 21-32.

de Tourdonnet S. (1998) Maîtrise de la qualité et de la pollution nitrique en production de laitues sous abri plastique, Ph.D. Thesis, Institut National Agronomique Paris-Grignon, Paris, France, 191 p.

Delerue J.F., Perrier E., Timmerman A., Rieu M. (1999) New computer tools to quantify $3 \mathrm{D}$ porous structures in relation with hyraulic properties, in: Feyen J., Wiyo K. (Eds.), Modelling of transport processes in soils at various scales in time and space, pp. 153-163.

Dexter A.R. (1976) Internal structure of tilled soil, J. Soil Sci. 27, 267278.

Dexter A.R. (2004) Soil physical quality: Part I. Theory, effects of soil texture, density, and organic matter, and effects on root growth, Geoderma 120, 201-214.

Dexter A.R., Birkás M. (2004) Prediction of the soil structures produced by tillage, Soil Till. Res. 79, 233-238.

Dexter A.R., Radke J.K., Hewitt J.S. (1983) Structure of a tilled soil as influenced by tillage treatment, wheat cropping and rainfall, Soil Sci. Soc. Am. J. 47, 570-575.

Farrell D.A., Greacen E.L., Gurr C.G. (1966) Vapour transfer in soil due to air turbulence, Soil Sci. 102, 305-313.

Green T.R., Ahuja L.R., Benjamin J.G. (2003) Advances and challenges in predicting agricultural management effects on soil hydraulic properties, Geoderma 116, 3-27.

Guerif J. (1994) Influence de la simplification du travail du sol sur l'état structural des horizons de surface : conséquences sur leurs 
propriétés physiques et leurs comportements mécaniques, in: Simplification du travail du sol, ed. INRA, Paris, pp. 13-33.

Guérif J., Richard G., Dürr C., Machet J.M., Recous S., Roger-Estrade J., (2001) A review of tillage effects on crop residue management, seedbed conditions and seedling establishment, Soil Till. Res. 61, $13-32$.

Hadas A. (1997) Soil tilth-the desired soil structural state obtained through proper soil fragmentation and reorientation processes, Soil Till. Res. 43, 7-40.

Hamza M.A., Anderson W.K. (2005) Soil compaction in cropping systems A review of nature, causes and possible solutions, Soil Till. Res. 82, 121-145.

Horton R., Ankeny M.D., Allmaras R.R. (1994) Effects of compaction on soil hydraulic properties in: Soane B.D., van Ouwerkerk C. (Eds.), Soil Compaction in Crop Production, Elsevier, Amsterdam, pp. 141-166.

Horn R., Taubner H., Wuttke M., Baumgartl T. (1994) Soil physical properties and processes related to soil structure, Soil Till. Res. 30, $187-216$.

Horn R., Baumgartl T., Kayser R., Baasch S. (1995) Effect of aggregate strength on changes in strength and stress distribution in structured bulk soils in: Hartge K.H., Stewart R. (Eds.), Soil Structure - its development and function, Adv. Soil Sci., pp. 31-52.

Keller T., Arvidsson J., Dexter A.R. (2007) Soil structures produced by tillage as affected by water content and the physical quality of soil, Soil Till. Res. 92, 45-52.

Kimball B.A., Lemon E.R. (1971) Air turbulence effects upon soil gas exchange, Soil Sci. Soc. Am. J. 35, 16-21.

Lamandé M. (2003) Effets de l'interaction des pratiques culturales et des communautés lombriciennes sur la structure du sol et son fonctionnement hydrique, Ph.D. Thesis, École Nationale Supérieure Agronomique de Rennes, Rennes, France, 118 p.

Leij F.J., Ghezzehei T.A., Or D. (2002) Modeling the dynamics of the pore-size distribution, Soil Till. Res. 64, 61-78.

Linden D.R. (1982) Predicting tillage effects on evaporation from the soil, in Predicting tillage effects on soil physical properties and processes, Vol. ASA Special publication number 44, pp. 117-132.

Lin H.S., McInnes K.J., Wilding L.P., Hallmark C.T. (1999) Effects of soil morphology on hydraulic properties. I. Quantification of soil morphology, Soil Sci. Soc. Am. J. 63, 948-954.

McCown R.L., Hammer G.L., Hargreaves J.N.L., Holzworth D.P., Freebairn D.F. (1996) APSIM: a novel software system for model development, model testing and simulation in agricultural systems research, Agr. Syst. 50, 255-271.

Manichon H. (1987) Observation morphologique de l'état structural et mise en évidence d'effets de compactage des horizons travaillés, in: Monnier G., Goss M.J. (Eds.), Soil Compaction and Regeneration. Balkena, Rotterdam/Boston, pp. 39-52.

Millán H., González-Posada M. (2005) Modelling soil water retention scaling. Comparison of a classical fractal model with a piecewise approach, Geoderma 125, 25-38.
Mualem Y., Assouline S. (1989) Modeling soil seal as a non-uniform layer. Water Resour. Res. 25, 2101-2108.

Ndiaye B., Molénat J., Hallaire V., Gascuel C., Hamon Y. (2007) Effects of agricultural practices on hydraulic properties and water movement in soils in Brittany (France), Soil Till. Res. 93, 251-263.

Ojeniyi S.O., Dexter A.R. (1983) Changes in the structure of differently tilled soil in a growing season, Soil Till. Res. 3, 39-46.

Ojeniyi S.O., Dexter A.R. (1984) Effect of soil structure on soil water status, Soil Till. Res. 4, 371-379.

Or D., Leij F.J., Snyder V., Ghezzehei T.A. (2000) Stochastic model for post-tillage soil pore space evolution, Water Resour. Res. 36, 16411652.

Reicosky D.C., Voorhees W.B., Radke J.K. (1981) Unsaturated flow through a simulated wheel track, Soil Sci. Soc. Am. J. 45, 3-8.

Richard G., Boizard H., Roger-Estrade J., Boiffin J., Guérif J. (1999) Field study of soil compaction due to traffic: pore space and morphological analysis, Soil Till. Res. 51, 151-160.

Richard G., Sillon J.F., Marloie O. (2001) Comparison of inverse and direct evaporation methods for estimating soil hydraulic properties under different tillage practices, Soil Sci. Soc. Am. J. 65, 215-224.

Ritchie J., Singh V., Godwin D., Bowen W. (1998) Cereal growth, development and yield, in: Tsuji G., Hoogenboom G., Thornton P. (Eds), Understanding Options for Agricultural Production, Kluwer Academic Publishers, Dordrecht, The Netherlands, pp. 79-98.

Roger-Estrade J., Richard G., Caneill J., Boizard H., Coquet Y., Défossez P., Manichon H. (2004) Morphological characterization of soil structure in tilled fields. From a diagnosis method to the modelling of structural changes in tilled soils over time, Soil Till. Res. 79, $33-49$.

Roger-Estrade J., Richard G., Boizard H., Boiffin J., Caneill J., Manichon H. (2000) Modelling changes in the tilled layer structure over time as a function of cropping systems, Eur. J. Soil Sci. 51, 455-474.

Röver M., Heinemeyer O., Musch J.C., Kaiser E.-A. (1999) Spatial heterogeneity within the plough layer: high variability of $\mathrm{N}_{2} \mathrm{O}$ emissions rates, Soil Biol. Biochem. 31, 167-173.

Sain S.R., Shrikant J., Mearns L., Nychka D. (2006) A multivariate spatial model for soil water profiles, J. Agr. Biol. Env. Stat. 11, 462-480.

Sillon J.F., Richard G., Cousin I. (2003) Quantifying and modelling the effect of soil structure induced by tillage and traffic on soil drying, Geoderma 116, 29-46.

Simunek J., Jarvis N.J., van Genuchten M.Th., Gärdenas A. (2003) Review and comparison of models describing non-equilibrium and preferential flow and transport in the vadose zone, J. Hydrol. 272, $14-35$

Stenitzer E., Murer E. (2003) Impact of soil compaction upon soil water balance and maize yield estimated by the SIMWASER model, Soil Till. Res. 73, 43-56.

Watts C.W., Dexter A.R. (1994) Traffic and seasonal influences on the energy required for cultivation and the subsequent tilth, Soil Till. Res. 31, 303-322. 